\title{
Aquiles Montoya
}

\section{¿Desarrollo local o desarrollo comunitario?!}

\section{Introducción}

En este ensayo buscamos, fundamentalmente, deslindar teóricamente dos enfoques o visiones: la muy conocida del desarrollo local, auspiciada por gobiernos y organismos para gubemamentales, y la otra, la del desarrollo comunitario, surgida en y para las comunidades.

Ambas visiones aunque semejantes en sus nominaciones y con objetivos aparentemente comunes: buscan combatir la pobreza, son diferentes en su contenido, responden a iniciativas distintas, los centros de apoyo institucional son diferentes, los sujetos reales son otros y la finalidad última de ambas estrategias también es diferente y diferenciable.

\section{La visión del desarrollo local tradicional}

Allá, por la década de los cincuenta, un lío abuelo me comentaba que cuando él había sido alcalde del pueblo, un palestino que había llegado antes de la segunda guerra mundial y que se había establecido por aquellas tierras, siempre que conversaban le hacía la siguiente reflexión: "Vea, amigo, su gobiemo lo que debería hacer es fomentar la desconcentración de las actividades económicas. Si existieran estímulos para establecer negocios en las distintas localidades del interior, no sólo se resolverían los problemas de desempleo y delincuencia en estas zonas, sino que adicionalmente no habría migración hacia San Salvador, con la secuela de males y problemas que ello conlleva..." Traigo a cuenta lo anterior solamente para destacar que la idea del desarrollo local y la desconcentración geográfica de la aclividad económica, no sólo es algo muy lógico, sino que no es nuevo.

Sin embargo, lo lógico, lo obvio no siempre es aquello que termina por imponerse, sino que a menudo se hace todo lo contrario y es así como en nues- 
tro país, medio siglo después, seguimos sin realizar esfucrzos serios a fin de procurar la desconcentración geográfica de la actividad económica que posibilite la consecución del desarrollo local, pese a lo evidente que resulta ahora que el área metropolitana de San Salvador, ya no es capaz de albergar en condiciones humanas a una familia más, y ello sin mencionar los graves daños que se le infringen, día con día, al ecosistema.

La cuestión que resulta importante, entonces, no es si la idea de un presunto desarmollo local es o no aceptable, tal visión parece contar con un amplio consenso. El desarrollo local y regional se presenta como un proyecto aceptable y deseable sin dar lugar a mayores discusiones. Y esto es así porque la noción de desarrollo local implica o presupone un determinado resultado: el desarrollo como tal, lo cual implica mejores condiciones de vida y trabajo para toda la sociedad, en consecuencia, resulta casi imposible encontrar a alguien que se pueda oponer al mismo, aunque puede encontrarse una diversidad de opiniones cuando se trata del estilo de desarrollo. Por fortuna, en los últimos años, tal desacuerdo está resolviéndose mediante la visión del desarrollo sostenible, esto es, un estilo de desarrollo ecológicamente viable. Tal situación novedosa ha posibilitado que el discurso oficial, muy hábil para coptar las iniciativas progresistas, haya asumido como propia la expresión más que la concepción del desarrollo local sostenible y que, como lo veremos, infra haya reconvertido, al menos nominalmente, el Fondo de Inversión Social (FIS) en Fondo de Inversión Social para el Desarrollo Sostenible (FISDL).

El punto por debatir vendría a ser, entonces, cómo se entiende y cómo se podría alcanzar el pretendido desarrollo local; además de establecer cuáles serían sus objetivos, implicaciones y resultados o efectos. Y precisamente en este punto es en el que se presentan otras visiones alternativas, entre las que cabría mencionar al desarrollo comunitario, a la economía popular o al desarrollo alternativo, etc. Todos se refieren a una y la misma realidad procesal, pero no han logrado asumir una determinada denominación común o genérica, en razón de que al no tratarse de experiencias inducidas desde arriba, sino que surgidas desde abajo, cada experiencia se siente muy propia, muy especial y se llama a sí misma como mejor le parece.

\section{La visión gubernamental del desarrollo local}

Nuestro gobiemo, al igual que olros gobiemos del área, se manifiestan a favor de la consecución del desarrollo local; sin embargo, su concepción se reduce a las tradicionales obras sociales y/o de infraestructura, tales como la construcción de vías de comunicación, de escuelas, centros de salud, de introducción de agua potable y energía eléctrica, etc. En otras ocasiones, la labor de desarrollo queda reducida a un simple adoquinado de las calles que bordean el 
parque, la iglesia y la alcaldía de cualquier poblado o, bien, regalar unos cuantos almuerzos a los infantes de la escuela del lugar.

Por otra parte, esta visión del desarrollo local en comparación con las visiones del pasado presenta dos elementos novedosos: la descentralización y la participación ciudadanas, aunque en la mayoría de los casos, ello se quede en simples declaraciones oficiales o, cuando más, en buenos propósitos de los munícipes pero que nunca se alcanzan de manera real.

En la Propuesta de Plan Nacional de Gobiemo, el Partido Alianza Republicana Nacionalista, ARENA, buscaba ganar electores en 1994, entre otros muchos planteamientos, con los siguientes:

\section{Plan de Desarrollo Social}

\section{Estrategia global}

* Reestruclurar y modemizar los programas sociales, especialmente de salud, educación y vivienda, descentralizándolos, fortaleciendo a los Gobiemos Municipales, organizando y capacitando a las comunidades, para que su ejecución se realice con la participación de los beneficiarios.

* Fomentar y fortalecer la participación solidaria de las propias comunidades, organizaciones voluntarias, y los Gobiemos Municipales en la ejecución de programas sociales.

\section{Estrategia operativa}

* Transformar a los Gobiemos Municipales en actores principales en los procesos de identificación de los problemas y sus soluciones, ejecución de obras y programas y desarrollo de sus comunidades ${ }^{2}$.

Se podría pensar que la formulación se reduce exclusivamente a elementos de contenido social, porque citamos el ámbito social de la propuesta, precisamente; sin embargo, si queremos encontrar alguna referencia al desarrollo local tenemos que acudir al área social, ya que en el área económica no existe nada que tenga relación con esta temática, lo cual ya dice bastante de la percepción del desarrollo que se tiene, o bien, de cual ha de ser el rol del gobiemo en la consecución del mismo.

La pertinencia de nuestras aseveraciones se confirma cuando el partido ARENA, una vez en el poder, expresa por boca del presidente:

"En materia de desarrollo local y de reconstrucción, la Secretaría de Reconstrucción Nacional, invirtió setecientos millones de colones, beneficiando a más de un millón de personas. 
En el Programa Municipalidades en Acción, se ejecutaron mil trescientas obras de infraestructura económica básica en distintos municipios del país, con la participación directa de los Gobiemos Locales y de las Comunidades en Cabildos Abiertos.

Además, el Fondo de Inversión Social, benefició a más de cuatrocientos setenta mil salvadoreños en siluacion de pobreza, mediante proyectos de educación, salud, agua potable, electrificación, medio ambiente y olros, por un monto de más de doscientos ochenta y siete millones de colones" ${ }^{3}$.

Seguramente, para una mejor comprensión de lo anterior, sea pertinente explicitar cuáles son los objetivos de las instituciones oficiales vinculadas con lo que a juicio del gobiemo constituye el desarrollo local.

\section{A. Secretaría de Reconstrucción Nacional (SRN)}

El objetivo general de la Secretaría de Reconstrucción Nacional (SRN) consiste en contribuir a la realización de las metas del gobiemo a través de programas sociales compensatorios focalizados hacia los estratos poblacionales menos favorecidos con servicios básicos.

Objetivos específicos:

(a) Promover y fortalecer la participación de la comunidad en la solución de sus propias necesidades.

(b) Generar empleo temporal en comunidades pobres.

(c) Mejorar las condiciones de vida en las comunidades beneficiadas.

(d) Construir infraestructura básica y comunal`.

\section{B. Fondo de Inversión Social (FIS)}

Según el decreto de creación, el Fondo de Inversión Social (FIS) tiene como propósito fundamental atender las demandas apremiantes de la población en situación de pobreza, particularmente la extrema, para potenciar su capacidad de integración plena al desarrollo económico y social del pais ${ }^{5}$.

Sus actividades son las siguientes:

* educación, con ejecución de proyectos de infraestructura, equipamiento y dotación de recursos materiales educativos;

* salud y nutrición, proyectos de infraestructura, equipamiento;

* agua potable, alcantarillado y letrinización; 
- medio ambiente, proyectos de forestación, cocinas lorena y chefina;

" guarderías y hogares infantiles".

Algunos documenlos recientes informan que,

El destino de los fondos (del FIS) es el siguiente: 45.4 por ciento en proyectos de educación, guarderías y centros de capacitación; 42.9 por ciento se destinan para salud, letrinización, agua potable, alcantarillado y nutrición, y el resto para riego, forestación, cocinas, mercados y olros?

Durante el presente año y a raíz de un esfuerzo de carácter centroamericano en procura del desartollo sostenible, al menos esa es la retórica oficialista, el FIS se ha transformado en FISDL, Fondo de Inversión Social para el Desarrollo Sostenible. $O$ sea que al menos nominalmente ya contamos en el país con una institución orientada a conseguir el desarrollo sostenible. Ciertamente este tipo de instiluciones que practican la "caridad oficial" no son nuevas. En tiempos de Martínez existieron "El Botón Azul y la Gota de Leche"; luego de la Segunda Guerra Mundial el denominado "Punto Cuarto" con ayuda norteamericana, al igual que en tiempos de Kennedy la célebre "Alianza para el Progreso"; durante los años más fuertes de la guerra la "Comisión Nacional de Repoblación de Areas" (CONARA), luego el FIS y la SRN.

\section{Programa Municipalidades en Acción (MEA)}

El tipo de proyectos que se realiza bajo el programa (MEA) se relaciona con la construcción-reparación de escuelas, puestos y unidades de salud, construcción de vías de acceso, acueductos y alcantarillados, electrificación y otros.

Este es quizá uno de los mejores ejemplos de lo poco que a los gobiernos les interesa la participación ciudadana, llegándose al extremo de que, "... USAID comenzó a requerir que todos los proyectos de infraestructura fueran identificados a través de cabildos abiertos, de lo contrario no habría financiamiento"'.

Además de las instituciones antes señaladas existen otras propias de la visión municipalista: el Instituto Salvadoreño para el Desarrollo Municipal (ISDEM), que proporciona capacitación y asistencia técnica (a los funcionarios y empleados municipales)...; el Instituto Salvadoreño de Administración Municipal (ISAM), institución oficial para el desarrollo municipal creado en 1987; y la Corporación de Municipalidades de la República de El Salvador (COMURES), que es la institución líder en la promoción del diálogo alrededor de la política nacional de descentralización". Los Consejos Departamentales de Alcaldes (CDA), que como formas de organización intermedia de la Corporación, constituyen una instancia 
adecuada para coordinar, negociar y acordar las acciones entre los gobiemos central y local".

Por otra parte, el Código Municipal brinda las garantías para la autonomía municipal y la participación ciudadana por medio de los cabildos abiertos y las consultas populares. Los primeros se implementan más dado que no conllevan obligatoriedad en el cumplimiento de los acuerdos por parte de las autoridades municipales, y no así los segundos que sí obligan al cumplimiento de lo acordado en la "consulta"'2. Respecto a la autonomía municipal, ésta se manifiesta en las siguientes funciones que el Código Municipal asigna a las municipalidades:

(1) planificación, prestación y mantenimiento de algunos servicios públicos esenciales; (2) promoción y desarrollo de la educación, cultura, deportes, recreación y ciencias y artes dentro de la comunidad local; (3) creación de registros; (4) preparación, aprobación y ejecución de planes locales de desarollo urbano y local; (5) protección ambiental local y conservación de recursos naturales; (6) jurisdicción sobre servicios locales de transporte; (7) recolección y disposición de basura ${ }^{13}$.

La visión de desarrollo está manifiesta en los siguientes planteamientos de COMURES:

La Comisión Coordinadora del Proceso de Descentralización y Desartollo Municipal preparó, en años pasados, una Estrategia para la Descentralización, así como propuestas específicas sobre las posibles competencias a descentralizarse en 5 áreas prioritarias: educación, salud, agua y alcantarillado, construcción y mantenimiento de caminos y administración territorial local ${ }^{14}$.

Pero el aspecto importante y fundamental de cualquier estralegia de desarrollo -el componente económico- está ausente o simplemente se hacen votos para que la inicialiva privada emprenda inversiones locales. Sin embargo, cualquier "buena intención" de los empresarios es desmotivada por la objetividad de las maternáticas y el sólido argumento de la tasa de retorno del capital. Si es posible obtener una mayor rentabilidad con menores costos al invertir en los tradicionales centros urbanos, ¿qué sentido tiene arriesgarse en invertir en zonas desconocidas?

\subsection{Diferencias entre la visión gubernamental del desarrollo local y el desa- rrollo comunitario}

La forma en que el gobierno concibe e implementa el desarrollo local presenta las siguientes diferencias con la estrategia popular del desarrollo comunitario: 
Primero, los sujetos del desarrollo son considerados como actores, lo cual no se reduce a un simple problema nominal, sino que está expresando toda una concepción del desartollo. Al considerar a las personas como actores, de manera implícita se señala que aquellas deberán representar un papel que otros han formulado para ellas. La participación de las personas, como la de los actores, se limitaría a realizar una determinada interpretación, con la cual se puede o no estar de acuerdo, y se puede o no sentir, etc. Por ello, la participación a pesar de ser activa se limita a ser una simple representación. Muy distinto es lo que ocurre con el desarrollo comunitario, ya que en éste las personas son auténticos sujetos del proceso, el cual no les llega de ninguna parte, sino que son ellos quienes a base de prueba y error lo van creando. Ciertamente es un proceso más lento y mucho más difícil que cualquier otro, sin embargo, es mucho más seguro y duradero. En lo que a la participación respecta, ésta no es interpretativa como en el desarrollo local sino creativa, en tanto se impulsa un proceso de desarrollo que va generando una nueva realidad en desarrollo.

Segundo, el proyecto de desarrollo local está enfocado principalmente al fortalecimiento de satisfactores sociales, esto es, aquellos vinculados con salud y salubridad, educación y alguna infraestruclura de servicios como agua potable, energía eléctrica, comunicaciones, etc. y sólo de manera muy marginal hacia aquellos aspectos económicos que podrían asegurarle sostenibilidad a los satisfactores sociales. Desde esta perspectiva, el desarrollo local es asumido por el gobiemo en la forma tradicional con que se ha enfrentado el "desarrollo" y quizás las únicas novedades que presentaría serían las referidas a la descentralización de algunos servicios que, en ocasiones, caen en una especie de municipalización cuando no se logra la privatización de los mismos. Muy distinto es el enfoque que presenta el desarrollo comunitario, para éste la mayor preocupación e interés se encuentra en los aspectos económicos y su referencia a lo social resulta ser marginal o secundario en lérminos de enfoque. La cuestión es la siguiente: si se resuelve el problema de empleo e ingresos de las familias pobres, será posible que ellas vayan enfrentando por su propia cuenta las necesidades sociales de educación, salud, vivienda, etc. Mientras ello no se consigue, se procura promover aquellos proyectos que resulten necesarios para satisfacer tales necesidades ya sea en colaboración con el gobiemo o con el apoyo de la cooperación externa. Pero lo relevante es que han comprendido que de muy poco sirve que se les provea de infraestruclura educativa, por ejemplo, si no se cuenta con empleo e ingresos que posibiliten su alimentación para estar vivos y dispuestos a recibir la educación que se les ofrece. Lo primero y fundamental en esta visión del desarrollo es que las personas tengan las condiciones económicas necesarias para asegurarse su reproducción material; garantizado este elemento de vida y trabajo, de ingresos y capacidad de compra, resulta posible contar de manera sostenible con todos los satisfactores sociales necesarios para una vida humana digna. 
Tercero, los procesos de desarrollo local al ser promovidos a iniciativa de los gobiernos o instituciones paragubernamentales, es obvio que aunque se presenten con la intención de resolver los problemas de pobreza y marginación social, a los promotores les basta y complace lograr sólo desactivar los mecanismos de explosividad social. Lo importante no es que se acabe la pobreza sino que los pobres no protesten, se domestiquen y crean que si bien ellos no han logrado salir de la ignominiosa pocilga en que crecieron, existe una clara oportunidad para que sus hijos lo logren. Por todo ello expresan un presunto "amor por la democracia", que no significa otra cosa que defender la preservación del sistema capitalista, el sistema de la libre empresa y de las oportunidades para todos. El desarrollo local al ser tal, encuentra con muchísima facilidad recursos financieros para implementar sus proyectos. Los procesos de desarrollo comunitario en cambio, al ser promovidos por los pobres en asociación libre con algunos Organismos no gubemamentales comprometidos con los mismos, aunque no expresen de manera explícita su disposición de trabajar para crear una sociedad nueva, que genere desde la base, desde "abajo", los cimientos de una forma de organización social distinta en la cual se superen los males inherentes a la sociedad capitalista, es obvio que tienen que asumir los retos y los costos del ser revolucionario. Esta es una de las razones por las cuales las comunidades no cuentan con el apoyo del gobierno y tampoco logran tener acceso a una amplia gama de donantes, y se tienen que conformar sólo con un tipo de cooperantes, aquellos llamados solidarios que ofrecen su ayuda sin condiciones ni restricciones.

Cuarso, los actores del desarrollo local cuando cuentan con una determinada organización, más que ser algo consuslancial a su estrategia de vida la han creado formalmente para tener acceso a los recursos proporcionados por donantes extranjeros, o bien, para ser declarados beneficiarios de algún proyecto específico del gobierno, aunque en la generalidad de los casos se ve al caserío, al canlón o al municipio como una comunidad, aunque no cuenten ni siquiera con una organización formal para los sujetos del desarrollo comunitario. En cambio, la organización con fines económicos es algo fundamental y consustancial a la realidad de las comunidades populares. Se organizan -cooperativa, comunitaria o solidariamente - para solventar de mejor manera sus necesidades materiales y espirituales. Para luchar contra su marginalidad social, la mayoría de las veces con el convencimiento de que en forma individual nunca pudieron encontrar respuestas, ni salidas a sus condiciones miserables de vida y trabajo. En muchas ocasiones sus estralegias están orientadas a poseer trabajo y, consecuentemente, algún ingreso. Muchas comunidades viven en condiciones de reproducción simple, lo cual se considera como un elemento negativo ya que podría conducir al fracaso de estas experiencias; sin embargo, habría que recordar que las sociedades pueden vivir muchísimos años aun en condiciones de crecimiento cero, recuérdese al feudalismo, por ejemplo. No obstante, dentro de las experiencias de 
desarrollo comunitario, las posibilidades de remontar las condiciones de reproducción simple son menos difíciles que aquellas que presentaba el feudalismo y, en muchos casos, bastaría con superar algunas limitantes como las deficiencias en la comercialización, en la gestión financiera y la poca o ninguna interrelación comunitaria, para lograr un cierto crecimiento económico.

\section{El concepto de desarrollo local}

Entre los expertos del desartollo local se encuentra Francisco Alburquerque, director de Desarrollo y Gestión Local del ILPES, quien sostiene que a diferencia de las visiones tradicionales del desarrollo que buscaban tan sólo la posibilidad de atraer inversión extranjera, la concepción actual del desarrollo local “... se basa en la identificación y aprovechamiento de los recursos y potencialidades endógenos a nivel local"'s.

Otros elementos que fortalecen su argumentación son, primero:

En esta perspectiva, comenzó a adquirir mayor importancia el análisis de las potencialidades endógenas de cada territorio, incluyendo en ello no sólo los factores económicos o la dotación de recursos, sino los factores no económi$\cos$ (sociales, culturales, históricos, institucionales, paisajísticos, elc.), los cuales son también decisivos en el proceso de desartollo económico local ${ }^{1 \mathrm{th}}$.

En segundo lugar hace referencia a otro grupo de elementos:

Las políticas macroeconómicas, al operar desde una perspectiva muy agregada, se ven imposibilitadas para captar las dimensiones locales, sociales o ambientales de cada territorio concrelo; mientras que - por el contrario- el enfoque del desarrollo económico endógeno (o desarrollo local) permite redescubrir e impulsar las potencialidades existentes en el medio natural y el tejido económico y social territorial ${ }^{17}$.

Sin embargo, pese a su carácter novedoso, Alburquerque termina por conceder que su perspectiva de desarrollo local no es más que un complemento a los programas de ajuste estructural cuando dice:

En otras palabras, se constata la necesidad de acompañar los procesos de ajuste macroeconómico con polílicas más específicas o adecuadas a las caraclerísticas territoriales concretas, en cuyo diseño y aplicación es fundamental la participación de los diferentes agentes sociales locales.

Como se ve, no se trata de presentar el desarrollo económico endógeno como un "modelo altemativo" de funcionamiento al sistema de acumulación capitalista actual, sino de constalar la heterogeneidad de dicho proceso de acumulación a fin de diseñar las diferentes políticas y líneas de actuación concretas en cada caso. 
No se niega, por tanto, la existencia de las fracciones hegemónicas del capital, y la lógica de concentración propia de las grandes empresas... ${ }^{\text {t8 }}$

Luego de haber presentado los planteamientos anteriores es posible ocuparnos de la definición de desartollo local que propone el autor, sin riesgo de esperar más de lo que puede dar esta concepción del desarrollo local:

Podemos, pues, definir Desarrollo Económico Local como un proceso de transformación de la economía y la sociedad locales, orientado a superar las dificultades y retos existentes, que busca mejorar las condiciones de vida de su población mediante una actuación decidida y concertada entre los diferentes agentes socioeconómicos locales (públicos y privados), para el aprovechamiento más eficiente y sustentable de los recursos endógenos existentes, mediante el fomento de las capacidades de emprendimiento empresarial locales y la creación de un entorno innovador en el territorio's.

Antes de concluir este apartado hay que señalar que en uno de los departamentos de nuestro país se está siguiendo - al menos parcialmente - la visión de desarrollo local propuesta por Alburquerque. Se trata del departamento de Chalatenango, en donde es posible observar la concertación, vía la Agencia de Desarrollo Local (ADEL), en la que además de los empresarios capitalistas participan las comunidades, las autoridades municipales, los diputados, algunos ministerios, universidades y varios organismos no gubemamentales.

\section{Consideraciones finales}

En nuestra concepción del desarrollo comunitario, la visión del desartollo local no se presenta como algo incompatible o excluyente, sin embargo, sí lo concebimos como algo muy diferente. Aunque se puede aprovechar mucho de lo que se promueve y realiza bajo la visión del desarrollo local, no se debe permitir que se mediatice el desarrollo comunitario concebido como una estrategia alternativa al desarrollo local y al sistema mismo. Así, por ejemplo, toda la obra social es bienvenida para el desarrollo de las comunidades, ya que de esa manera no sólo se resuelven algunos problemas sociales de la población sino que se liberan recursos de las comunidades, los cuales pueden ser empleados en proyectos de carácter económico. Por otra parte, en la actualidad, el desarrollo comunitario se encuentra en condiciones bastante precarias por su carácter embrionario. A partir de esto, los esfuerzos propios del desarrollo local tendientes a generar crecimiento económico en las localidades pueden inducir una mayor actividad económica dentro de las comunidades, siempre y cuando las actividades económicas generadas no sean incompatibles con las de las comunidades, sino más bien se presenten con carácter complementario y, por tanto, no vengan a reemplazar a las iniciativas populares. 
Ciertamente, la concepción del desarrollo local ni su implementación se presentan como los mayores riesgos para la visión y estrategia del desarrollo comunitario, ya que el primero puede ser absorbido por el segundo, si se tiene la claridad necesaria para hacerlo. El mayor problema que presenta la estrategia comunitaria es su atomización geográfica y la carencia, por parte de sus dirigentes, de una visión totalizadora que les permila superar sus deficiencias mediante la articulación de las distintas experiencias particulares entre sí, antes que hacerlo con las empresas capitalistas.

\section{Notas}

1. Ponencia efectuada en el Forum Comunity Economic Development. "Docs it Work? Perspectives from Latin America and Allantic Canada”, Saint Mary's University, Canada.

2. Propuesta de Plan Nacional de Gobierno Alianza Republicana Nacionalista, ARENA, 1994-1999.

3. Discurso pronunciado por el presidente de la República en ocasión de celebrar el scgundo año de su gestión presidencial, junio de 1996.

4. Ramírez Víctor A. "Indicadores básicos y gasto social a nivel municipal", en El Salvador: Diagnóstico y Propuestos para el Desarrollo Municipal, FUNDAUNGO, COMURES, aulores varios, San Salvador, 1997, p.17.

5. Ibid., p. 14.

6. Ibid., p. 16.

7. Ibid., p. 23.

8. Ibid., p. 19.

9. Ibid., p. 18.

10. Ibid., p. 19.

11. COMURES, Propuesta sobre el Desarrollo Local, la Descentralización y los Gobiernos Municipales, "El Salvador: Diagnóstico y Propueslas para el Desarrollo Municipal", FUNDAUNGO, COMURES, autores varios, San Salvador, 1997, p. 129.

12. El Código Municipal data de fecha tan reciente como 1986.

13. Evaluación de la Polílica de Descentralización y Desarrollo Municipal, ISAM, Víctor Antonio Orellana, el al, San Salvador, 1995, p. 85.

14. Ibíd., p. 127.

15. Alburquerque, Francisco, "Mctodología para el Desarrollo Económico Local, Dirccción de Desarrollo y Gestión Local”, ILPES, febrero, 1997, mimco, p. 1.

16. Ibíd., p. 6.

17. Ibid., p. 7.

18. Ibid., ps. 7-8.

19. Ibid., p. 10. 